\title{
Immune-related adverse events associated with PD-1/PD-L1 Inhibitors used as first-line treatment for advanced non-small cell lung cancer: a Bayesian network meta-analysis of randomized clinical trials
}

\author{
Jingjing Gu ( $\sim 958680821 @ q q . c o m)$ \\ Lianyungang Second People's Hospital \\ Weidong Zhang \\ Xixi Hospital of Hangzhou \\ Chunming Bian \\ Lianyungang Second People'sHospital \\ Guanhong Huang \\ Lianyungang Second People's Hospital
}

\section{Research}

Keywords: Immune-related adverse events, Non-small cell lung cancer, Network meta-analysis, Immune checkpoint inhibitors,

Posted Date: March 1st, 2021

DOI: https://doi.org/10.21203/rs.3.rs-248839/v1

License: @ (i) This work is licensed under a Creative Commons Attribution 4.0 International License. Read Full License 


\section{Abstract \\ Background}

In recent years programmed cell death receptor 1 (PD-1) and its ligand, programmed cell death ligand-1 (PD-L1), have opened a new era of advanced non-small cell lung cancer (NSCLC) treatment,while yielding higher rates of immune-related adverse events (irAEs) than platinum-based chemotherapy. This network meta-analysis indirectly compared the incidences of irAEs of PD-1/PD-L1 inhibitor + chemotherapy, PD-1/PD-L1 inhibitor alone, and dual PD-1/PD-L1 inhibitor combinations.

\section{Methods}

We found 12 phase II or III randomized clinical trials (RCTs) including 8,453 patients with NSCLC by searching Pubmed, Embase, and the Cochrane Central Register of Controlled Trials, ClinicalTrials.gov. Summary risk ratios(RRs) and $95 \%$ confidence interval were used to compare the rate of irAEs for different ICl-based treatments using pairwise and network meta-analysis with random effects.

\section{Results}

In addition to platinum-based chemotherapy, in terms of dermatologic irAEs, durvalumab had the lowest rate compared to pembrolizumab + platinum, nivolumab, atezolizumab + platinum, nivolumab, pembrolizumab, nivolumab + ipilimumab. In terms of gastrointestinal irAEs, pembrolizumab had the lowest rate compared to nivolumab, nivolumab + ipilimumab, durvalumab, atezolizumab + platinum, and pembrolizumab + platinum. For endocrine irAEs, pembrolizumab + platinum had the lowest rate compared to pembrolizumab, atezolizumab + platinum, durvalumab, nivolumab, and nivolumab + ipilimumab. For pneumonitis, atezolizumab had the lowest rate compared to durvalumab nivolumab, atezolizumab + platinum, pembrolizumab + platinum, and pembrolizumab. For liver irAEs, durvalumab had the lowest rate compared to pembrolizumab, nivolumab, atezolizumab + platinum, pembrolizumab + platinum.

\section{Conclusions}

These findings suggested that, for patients with advanced NSCLC at high risk of irAEs, durvalumab for patients with dermatologic and liver irAEs, pembrolizumab for patients with gastrointestinal irAEs, pembrolizumab + platinum for patients with endocrine irAEs, and atezolizumab for patients with pneumonitis may be the preferred treatment regimens rather than other immune-based therapies.

\section{Simple Summary}

In recent years PD-1/PD-L1 Inhibitors, which constitute an inhibitory pathway detected in a variety of malignant tumors, have opened a new era of cancer treatment, while yielding higher rates of irAEs than platinum-based chemotherapy. Here, to help clinicians improve early management and identification of irAEs, we indirectly compared the incidences of irAEs by PD-1/PD-L1 inhibitor+chemotherapy, PD-1/PD-L1 inhibitor alone and dual PD-1/PD-L1 inhibitors combinations. Compared to previous studies, first, more patients with advanced NSCLC were included in this study, and all data were up to date. Second, this study only looked at NSCLC, and immune-related treatment regimens were more specific to each treatment regimen, which will help clinicians make better treatment choices based on patients' specific conditions. Third,all of the control experimen ts in our study were platinum-based chemotherapy, excluding docetaxelbased chemotherapy and others, which would reduce bias and increase credibility. Fourth, some conclusions this study drew were innovative compared to previous studies, which will have some significance for guiding clinical treatment and subsequent studies.

\section{Background}

According to the latest statistics, lung cancer is still the leading cause of cancer deaths, although the incidence of cancer has declined in recent years ${ }^{[1-2]}$. Nearly $70 \%$ of patients with lung cancer are diagnosed with locally advanced or metastatic disease[4], and the 5-year survival rate is only $5 \%[5-6]$. However around $80-85 \%$ of lung cancer cases are classified as NSCLC[3]. Platinum-based chemotherapy remains the standard first-line treatment for NSCLC without target gene mutations, with a response rate of only $15 \%[7-8]$.

In recent years PD-1/PD-L1 inhibitors, which constitute an inhibitory pathway detected in a variety of malignant tumors, have opened a new era of cancer treatment[9-10]. Treatment with PD-1/PD-L1 inhibitor alone or in combination makes longer survival possible[11-12].

Page 2/18 
Data from a series of randomized clinical trials suggest that PD-1/PD-L1 inhibitors alone or in combination as first-line treatment for advanced NSCLC patients provides better clinical benefits and fewer side effects than conventional platinum-based chemotherapy[1326]. However, PD-1/PD-L1 inhibitors enhance self immune functions against cancer cells through a unique mechanism that blocks negative regulators expressed on immune or tumor cells, while yielding higher rates of irAEs than platinum-based chemotherapy[26]. Immune-related adverse events may involve a number of organs or systems: dermatologic irAEs (pruritus and rash), gastrointestinal irAEs (diarrhea and constipation), endocrine irAEs (hypothyroidism and hyperthyroidism), pneumonitis and liver irAEs (increased alanine aminotransferase, increased aspartate aminotransferase level and hepatitis). These irAEs have attracted the attention of clinicians as they invoke a high rate of drug withdrawal and mortality. The occurrence of grade 3 or higher irAEs varied from $8-10 \%$ among patients with advanced NSCLC receiving PD-1/PD-L1 inhibitors. If not properly treated and managed in clinical practice, irAEs will lead to treatment termination, failure, and may even be life-threatening.

Here, to help clinicians improve early management and identification of irAEs, a Bayesian network meta-analysis was conducted to compare the incidences of irAEs and rank the safety of PD-1/PD-L1 inhibitor + chemotherapy, PD-1/PD-L1 inhibitor alone, and dual PD1/PD-L1 inhibitor combinations.

\section{Methods}

\subsection{Data sources and searches}

This network meta-analysis (NMA) was based entirely on the preferred reporting items for systematic reviews and meta-analysis (PRISMA) ${ }^{[27-28]}$ and PRISMA extended guidelines for an NMA. RCTs on PD-1/PD-L1 inhibitors versus platinum-based chemotherapy as the first-line treatment of advanced NSCLC from 2015 to 2020 were searched in PubMed, Embase, the Cochrane Library, and Web of Science databases. To search for data not explicitly given in the RCTs, the National Institutes of Health ongoing Trial Registry (Clinicaltrials.gov) was also searched. A combination of MeSH and free-text words was searched according to the PICOS principle.Search terms and their combinations used in the search strategy included: (PD-1 OR PD-L1 OR nivolumab OR pembrolizumab OR durvalumab OR atezolizumab OR ipilimumab) AND (Non-Small-Cell Lung Carcinoma OR Non-Small Cell Lung Cancer) AND chemotherapy AND (randomized controlled trial). Two independent reviewers (Jingjing Gu and Weidong Zhang) conducted a preliminary screening of the searched topics and abstracts, and if they did not meet the criteria, further read the full text, and all references were evaluated as potentially relevant articles.

\subsection{Inclusion and exclusion criteria}

Inclusion criteria for RCTs of this NMA were as follows: (1) study type: only Phase II or III double blind RCTs for advanced NSCLC; (2) participants: included patients that were pathologically diagnosed as advanced NSCLC; (3) experimental group: patients were treated with immunotherapy alone or an immune-based combination as first-line treatment, control group: patients were treated with only platinum-based chemotherapy as first-line treatment; (4) outcome indicators: there was at least one irAE in the RCTs or searched on Clinicaltrials.gov.

Exclusion criteria: non-English articles, studies without valid data, reviews, meta-analyses, editorials, commentary letters, repeat studies.

\subsection{Data extraction}

By reading the titles, abstracts and full texts, the two authors screened out the articles that met the predetermined inclusion criteria. 1) Trial information, including first author, study year, trial id; 2) Stage information, study endpoint, and sample size of treatment; 3) Patient characteristics at baseline included median age, sex, and the numbers of patients with dermatologic irAEs, gastrointestinal irAEs, endocrine irAEs, pneumonitis and liver irAEs. And the two authors checked the extracted data before data analysis.

\subsection{Risk-of-bias assessment}

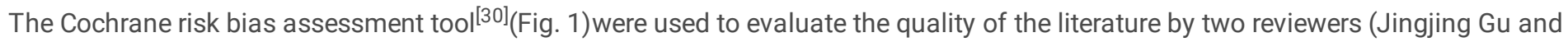
Weidong Zhang). The seven major sources of biases (random sequence generation, allocation concealment, blinding of participants and personnel, blinding of outcome assessment, incomplete outcome data, selective reporting and other bias) were classified into three grades including 'yellow represents unclear risk', 'green represents low risk' and 'red represents high risk' which were assessed using the Cochrane risk bias assessment tool.

\subsection{Outcome measures}


The study endpoints were dermatologic irAEs (pruritus and rash), gastrointestinal irAEs(diarrhea and constipation), endocrine irAEs

(hypothyroidism and hyperthyroidism ), pneumonitis and liver irAEs(increased alanine aminotransferase, increased aspartate aminotransferase level and hepatitis). Review criteria were based on the National Cancer Institute Common Terminology Criteria for Adverse Events ${ }^{[31]}$

\subsection{Data synthesis and statistical analysis}

The loops to illustrate the network geometry were generated using Stata13.0. In this Bayesian framework network meta-analysis, summary RRs and 95\% confidence intervals were used as the results of the effect size of PD-1/PD-L1 inhibitor-based drugs on the risk of irAEs in NSCLC patients. RR greater than 1 represented a low probability of irAEs in the control group. Markov chain Monte Carlo (MCMC) methods were used to establish random-effects and consistency models calculating the RR and 95\% confidence intervals within the Bayesian framework by using R(version 4.0.1) (CoreTeam 2019, Vienna, Austria) and JAGS (version 4.3.0) with the package"getmtc"(version 0.8.2) ${ }^{[32-33]}$. Heterogeneity of the included studies was assessed by $\mathrm{I}^{2}$ statistics. $\mathrm{I}^{2}$ values below $25 \%$, between $25 \%$ and $50 \%$, and above $50 \%$ represented low, medium, and high heterogeneity, respectively ${ }^{[34]}$. If the heterogeneity is low, the fixed effects model would be selected, otherwise the random effects model would be selected. In order to explore the inter-study heterogeneity of each outcome comparison, the values of different parameters of a log-normal distribution were fitted as a prior distribution ${ }^{[35]}$. To obtain the posterior distribution, 10,000 burn-ins and 50,000 iterations of 4 each chain and a thinning interval of 10 were generated for each outcome by using MCMC methods. We judged whether each MCMC chain reached a stable and good iteration during the calculation process through the Brookse-Gelmane-Rubin diagnostic plot with a cut-off value of 1 , so as to determine whether the degree of convergence of the model was satisfactory. The surface under the cumulative ranking curve (SUCRA) metric was used to rank the probabilities of irAEs of each treatment and identify the best treatment. In this network meta-ananlysis the SUCRA value ranged from 1 to 0 , representing the worst and best treatment regimes ${ }^{[36]}$. A funnel plot was used to assess the publication bias and symmetrical distribution in funnel plot suggests no publication bias ${ }^{[3]}$. Sensitivity analysis was performed to assess the stability of the results which were considered stable if there was significant consistency between direct and indirect results ${ }^{[38]}$. We conducted a inconsistency test(that is, the comparison of the differences between direct and indirect comparisons) using the nodal analysis and $P>0.05$ indicated that there is no inconsistency ${ }^{[39-40]}$.

\section{Results}

\subsection{Literature search results and study characteristics}

Through the literature search, 539 studies were initially retrieved. After removing duplicates, 352 studies were used to filter through screening titles and abstracts, then 39 studies were assessed by screening full text. Finally, 12 RCTs[13-24]including 8,453 patients were considered eligible for inclusion in this network meta-analysis. The literature retrieval strategy is shown in Fig. 2. The included RCTs

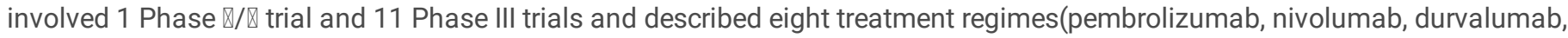
atezolizumab, pembrolizumab + platinum, atezolizumab + platinum, nivolumab + ipilimumab and platinum-based chemotherapy). The Network diagrams of comparisons on all outcomes in this network meta-analysis are presented in Fig. 3 . The dermatologic irAEs(pruritus and rash), gastrointestinal irAEs(diarrhea and constipation) and endocrine irAEs(hypothyroidism and hyperthyroidism) involved seven different treatment regimens(pembrolizumab, nivolumab, durvalumab, pembrolizumab + platinum, atezolizumab + platinum, nivolumab + ipilimumab and platinum-based chemotherapy) in 11 studies $^{[13-21,23]}$ (Fig. 3A). The pneumonitis involved seven different treatment regimens(pembrolizumab, nivolumab, durvalumab, atezolizumab, pembrolizumab + platinum, atezolizumab + platinum, nivolumab + ipilimumab and platinum-based chemotherapy) in 11 studies ${ }^{[13-22]}$ (Fig. 3B), and liver irAEs(Increased ALT level,Increased AST level and hepatitis ) involved six different treatment regimens(pembrolizumab, nivolumab, durvalumab, atezolizumab, pembrolizumab + platinum, atezolizumab + platinum) in 10 studies $^{[13-21]}$ (Fig. 3C). Key features of all the studies are shown in Tables 1 and 2. 
Table 1

General characteristics of the included randomised control trials for this network meta-analyses.

\begin{tabular}{|c|c|c|c|c|c|c|}
\hline $\begin{array}{l}\text { First } \\
\text { author,year }\end{array}$ & Study ID & Region & $\begin{array}{l}\text { Trial } \\
\text { phase }\end{array}$ & $\begin{array}{l}\text { Trail } \\
\text { number }\end{array}$ & Experimental group & Control group \\
\hline $\begin{array}{l}\text { Carbone } \\
2017\end{array}$ & $\begin{array}{l}\text { Checkmate } \\
026\end{array}$ & $\mathrm{MN}$ & 口 & 423 & Nivolumab 3mg/kg & $\begin{array}{l}\text { Platinum-based } \\
\text { chemotherapy }\end{array}$ \\
\hline Naiyer 2020 & Mystic & $\mathrm{MN}$ & 口 & 721 & Durvalumab 20 mg/kg & $\begin{array}{l}\text { Platinum-based } \\
\text { chemotherapy }\end{array}$ \\
\hline \multirow[t]{2}{*}{$\begin{array}{l}\text { Paz-Ares } \\
2018\end{array}$} & \multirow[t]{2}{*}{$\begin{array}{l}\text { Keynote- } \\
407\end{array}$} & \multirow[t]{2}{*}{ USA } & \multirow[t]{2}{*}{$\square$} & \multirow[t]{2}{*}{559} & $\begin{array}{l}\text { Pembrolizumab 200mg + } \\
\text { platinum-based }\end{array}$ & \multirow[t]{2}{*}{$\begin{array}{l}\text { Platinum-based } \\
\text { chemotherapy }\end{array}$} \\
\hline & & & & & chemotherapy & \\
\hline \multirow[t]{2}{*}{$\begin{array}{l}\text { Gandhi } \\
2018\end{array}$} & \multirow[t]{2}{*}{$\begin{array}{l}\text { Keynote- } \\
189\end{array}$} & \multirow[t]{2}{*}{ MN } & \multirow[t]{2}{*}{$\square$} & \multirow[t]{2}{*}{616} & $\begin{array}{l}\text { Pembrolizumab } 200 \mathrm{mg}+ \\
\text { platinum-based }\end{array}$ & \multirow[t]{2}{*}{$\begin{array}{l}\text { Platinum-based } \\
\text { chemotherapy }\end{array}$} \\
\hline & & & & & chemotherapy & \\
\hline Mok 2019 & $\begin{array}{l}\text { Keynote- } \\
042\end{array}$ & $\mathrm{MN}$ & 口 & 1274 & Pembrolizumab 200mg & $\begin{array}{l}\text { Platinum-based } \\
\text { chemotherapy }\end{array}$ \\
\hline Reck 2019 & $\begin{array}{l}\text { Keynote- } \\
024\end{array}$ & $\mathrm{MN}$ & प & 305 & Pembrolizumab 200mg & $\begin{array}{l}\text { Platinum-based } \\
\text { chemotherapy }\end{array}$ \\
\hline \multirow[t]{2}{*}{$\begin{array}{l}\text { Borghaei } \\
2016\end{array}$} & \multirow[t]{2}{*}{$\begin{array}{l}\text { Keynote- } \\
021\end{array}$} & \multirow[t]{2}{*}{$\begin{array}{l}\text { USA, } \\
\text { Taiwan }\end{array}$} & \multirow[t]{2}{*}{ 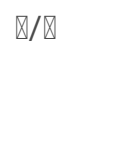 } & \multirow[t]{2}{*}{123} & $\begin{array}{l}\text { Pembrolizumab 200mg + } \\
\text { platinum-based }\end{array}$ & \multirow[t]{2}{*}{$\begin{array}{l}\text { Platinum-based } \\
\text { chemotherapy }\end{array}$} \\
\hline & & & & & Chemotherapy & \\
\hline \multirow[t]{2}{*}{ Rivero 2018} & \multirow[t]{2}{*}{$\begin{array}{l}\text { Impower } \\
132\end{array}$} & \multirow[t]{2}{*}{$\mathrm{MN}$} & \multirow[t]{2}{*}{ प } & \multirow[t]{2}{*}{578} & $\begin{array}{l}\text { Atezolizumab } 1200 \mathrm{mg}+ \\
\text { platinum-based }\end{array}$ & \multirow[t]{2}{*}{$\begin{array}{l}\text { Platinum-based } \\
\text { chemotherapy }\end{array}$} \\
\hline & & & & & Chemotherapy & \\
\hline \multirow[t]{2}{*}{ Robert 2018} & \multirow[t]{2}{*}{$\begin{array}{l}\text { Impower } \\
131\end{array}$} & \multirow[t]{2}{*}{$\mathrm{MN}$} & \multirow[t]{2}{*}{ ૧ } & \multirow[t]{2}{*}{1021} & $\begin{array}{l}\text { Atezolizumab } 1200 \mathrm{mg}+ \\
\text { platinum-based }\end{array}$ & \multirow[t]{2}{*}{$\begin{array}{l}\text { Platinum-based } \\
\text { chemotherapy }\end{array}$} \\
\hline & & & & & Chemotherapy & \\
\hline \multirow[t]{2}{*}{ West 2019} & \multirow[t]{2}{*}{$\begin{array}{l}\text { Impower } \\
130\end{array}$} & \multirow[t]{2}{*}{$\mathrm{MN}$} & \multirow[t]{2}{*}{$\square$} & \multirow[t]{2}{*}{724} & $\begin{array}{l}\text { Atezolizumab } 1200 \mathrm{mg}+ \\
\text { platinum-based }\end{array}$ & \multirow[t]{2}{*}{$\begin{array}{l}\text { Platinum-based } \\
\text { chemotherapy }\end{array}$} \\
\hline & & & & & Chemotherapy & \\
\hline Spigel 2019 & $\begin{array}{l}\text { Impower } \\
110\end{array}$ & $\mathrm{MN}$ & प & 572 & Atezolizumab 1200mg & $\begin{array}{l}\text { Platinum-based } \\
\text { chemotherapy }\end{array}$ \\
\hline $\begin{array}{l}\text { Hellmann } \\
2018\end{array}$ & $\begin{array}{l}\text { Checkmate } \\
227\end{array}$ & $\mathrm{MN}$ & प & 1537 & Nivolumab 3mg/kg] & $\begin{array}{l}\text { Platinum-based } \\
\text { chemotherapy }\end{array}$ \\
\hline & & & & & $\begin{array}{l}\text { Nivolumab } 3 \text { mg/kg + Ipilimumab } \\
1 \mathrm{mg} / \mathrm{kg}\end{array}$ & \\
\hline
\end{tabular}


Table 2

Patient characteristics and extracted data for study end-points in the included randomised controlled trials.

\begin{tabular}{|c|c|c|c|c|c|c|c|}
\hline Study ID & Treatment & $\begin{array}{l}\text { Trail } \\
\text { number }\end{array}$ & $\begin{array}{l}\text { Dermatologic } \\
\text { irAEs(pruritus } \\
\text { and rash) }\end{array}$ & $\begin{array}{l}\text { Gastrointestinal } \\
\text { irAEs(diarrhea } \\
\text { and } \\
\text { constipation) }\end{array}$ & $\begin{array}{l}\text { Endocrine irAEs } \\
\text { (hypothyroidism } \\
\text { and } \\
\text { hyperthyroidism } \\
\text { ) }\end{array}$ & Pneumonitis & $\begin{array}{l}\text { Liver } \\
\text { irAEs(Increased } \\
\text { ALT } \\
\text { level,Increased } \\
\text { AST level and } \\
\text { hepatitis ) }\end{array}$ \\
\hline \multirow[t]{2}{*}{$\begin{array}{l}\text { Checkmate } \\
026\end{array}$} & $\begin{array}{l}\text { Nivolumab } \\
3 \mathrm{mg} / \mathrm{kg}\end{array}$ & 267 & 92 & 105 & 20 & 23 & 60 \\
\hline & $\begin{array}{l}\text { Platinum-based } \\
\text { chemotherapy }\end{array}$ & 263 & 48 & 133 & 7 & 17 & 36 \\
\hline \multirow[t]{2}{*}{ Mystic } & $\begin{array}{l}\text { Durvalumab } 20 \\
\mathrm{mg} / \mathrm{kg}\end{array}$ & 369 & 107 & 72 & 40 & 32 & 33 \\
\hline & $\begin{array}{l}\text { Platinum-based } \\
\text { chemotherapy }\end{array}$ & 352 & 88 & 58 & 4 & 23 & 37 \\
\hline \multirow[t]{4}{*}{$\begin{array}{l}\text { Keynote- } \\
407\end{array}$} & $\begin{array}{l}\text { Pembrolizumab } \\
200 \mathrm{mg}\end{array}$ & 278 & 92 & 147 & 82 & 25 & 58 \\
\hline & $\begin{array}{l}+ \text { platinum- } \\
\text { based }\end{array}$ & & & & & & \\
\hline & Chemotherapy & & & & & & \\
\hline & $\begin{array}{l}\text { Platinum-based } \\
\text { chemotherapy }\end{array}$ & 280 & 58 & 126 & 14 & 8 & 23 \\
\hline \multirow[t]{3}{*}{$\begin{array}{l}\text { Keynote- } \\
189\end{array}$} & $\begin{array}{l}\text { Pembrolizumab } \\
200 \mathrm{mg}+ \\
\text { platinum-based }\end{array}$ & 405 & 145 & 266 & 43 & 18 & 116 \\
\hline & chemotherapy & & & & & & \\
\hline & $\begin{array}{l}\text { Platinum-based } \\
\text { chemotherapy }\end{array}$ & 202 & 50 & 107 & 11 & 5 & 35 \\
\hline \multirow[t]{2}{*}{$\begin{array}{l}\text { Keynote- } \\
042\end{array}$} & $\begin{array}{l}\text { Pembrolizumab } \\
\text { 200mg }\end{array}$ & 636 & 107 & 130 & 116 & 104 & 170 \\
\hline & $\begin{array}{l}\text { Platinum-based } \\
\text { chemotherapy }\end{array}$ & 615 & 44 & 212 & 13 & 41 & 181 \\
\hline \multirow[t]{2}{*}{$\begin{array}{l}\text { Keynote- } \\
024\end{array}$} & $\begin{array}{l}\text { Pembrolizumab } \\
\text { 200mg }\end{array}$ & 154 & 42 & 31 & 27 & 19 & 33 \\
\hline & $\begin{array}{l}\text { Platinum-based } \\
\text { chemotherapy }\end{array}$ & 150 & 6 & 38 & 5 & 2 & 34 \\
\hline \multirow[t]{3}{*}{$\begin{array}{l}\text { Keynote- } \\
021\end{array}$} & $\begin{array}{l}\text { Pembrolizumab } \\
200 \mathrm{mg}+ \\
\text { platinum-based }\end{array}$ & 59 & 22 & 23 & 14 & 2 & 19 \\
\hline & Chemotherapy & & & & & & \\
\hline & $\begin{array}{l}\text { Platinum-based } \\
\text { chemotherapy }\end{array}$ & 62 & 11 & 12 & 4 & 0 & 12 \\
\hline \multirow[t]{3}{*}{$\begin{array}{l}\text { Impower } \\
132\end{array}$} & $\begin{array}{l}\text { Atezolizumab } \\
1200 \mathrm{mg}+ \\
\text { platinum-based }\end{array}$ & 291 & 75 & 10 & 23 & 16 & 13 \\
\hline & Chemotherapy & & & & & & \\
\hline & $\begin{array}{l}\text { Platinum-based } \\
\text { chemotherapy }\end{array}$ & 274 & 60 & 4 & 6 & 6 & 2 \\
\hline $\begin{array}{l}\text { (Abbreviati } \\
\text { MN,multina }\end{array}$ & $\begin{array}{l}\text { ALT, alanine am } \\
\text { ial;NA, not appli }\end{array}$ & $\begin{array}{l}\text { transf } \\
\text { le.) }\end{array}$ & ; AST, aspar & aminotransfer & rAE, immune-re & adverse ev & \\
\hline
\end{tabular}




\begin{tabular}{|c|c|c|c|c|c|c|c|}
\hline Study ID & Treatment & $\begin{array}{l}\text { Trail } \\
\text { number }\end{array}$ & $\begin{array}{l}\text { Dermatologic } \\
\text { irAEs(pruritus } \\
\text { and rash) }\end{array}$ & $\begin{array}{l}\text { Gastrointestinal } \\
\text { irAEs(diarrhea } \\
\text { and } \\
\text { constipation) }\end{array}$ & $\begin{array}{l}\text { Endocrine irAEs } \\
\text { (hypothyroidism } \\
\text { and } \\
\text { hyperthyroidism } \\
\text { ) }\end{array}$ & Pneumonitis & $\begin{array}{l}\text { Liver } \\
\text { irAEs(Increased } \\
\text { ALT } \\
\text { level,Increased } \\
\text { AST level and } \\
\text { hepatitis ) }\end{array}$ \\
\hline \multirow[t]{3}{*}{$\begin{array}{l}\text { Impower } \\
131\end{array}$} & $\begin{array}{l}\text { Atezolizumab } \\
1200 \mathrm{mg}+ \\
\text { platinum-based }\end{array}$ & 334 & 74 & 104 & 34 & 23 & 58 \\
\hline & Chemotherapy & & & & & & \\
\hline & $\begin{array}{l}\text { Platinum-based } \\
\text { chemotherapy }\end{array}$ & 334 & 39 & 94 & 4 & 5 & 29 \\
\hline \multirow[t]{3}{*}{$\begin{array}{l}\text { Impower } \\
130\end{array}$} & $\begin{array}{l}\text { Atezolizumab } \\
1200 \mathrm{mg}+ \\
\text { platinum-based }\end{array}$ & 473 & 119 & 199 & 53 & 62 & 30 \\
\hline & Chemotherapy & & & & & & \\
\hline & $\begin{array}{l}\text { Platinum-based } \\
\text { chemotherapy }\end{array}$ & 232 & 28 & 77 & 1 & 22 & 14 \\
\hline \multirow[t]{2}{*}{$\begin{array}{l}\text { Impower } \\
110\end{array}$} & $\begin{array}{l}\text { Atezolizumab } \\
1200 \mathrm{mg}\end{array}$ & 286 & NA & NA & NA & 14 & NA \\
\hline & $\begin{array}{l}\text { Platinum-based } \\
\text { chemotherapy }\end{array}$ & 263 & NA & NA & NA & 17 & NA \\
\hline \multirow[t]{3}{*}{$\begin{array}{l}\text { Checkmate } \\
227\end{array}$} & $\begin{array}{l}\text { Nivolumab } \\
3 \mathrm{mg} / \mathrm{kg}\end{array}$ & 576 & 73 & 50 & 25 & NA & NA \\
\hline & $\begin{array}{l}\text { Nivolumab } \\
3 \mathrm{mg} / \mathrm{kg}+ \\
\text { Ipilimumab } \\
1 \mathrm{mg} / \mathrm{kg}\end{array}$ & 391 & 117 & 117 & 67 & NA & NA \\
\hline & $\begin{array}{l}\text { Platinum-based } \\
\text { chemotherapy }\end{array}$ & 570 & 34 & 141 & 0 & NA & NA \\
\hline
\end{tabular}

\subsection{Head-to-head comparisons for the endpoints}

In addition to platinum-based chemotherapy, in terms of dermatologic irAEs, durvalumab had the lowest rate compared to pembrolizumab + platinum ( $R R, 0.62,95 \% \mathrm{Cl}, 0.17$ to 2.26 ), nivolumab ( $R R, 0.42,95 \% \mathrm{Cl}, 0.11$ to 1.66 ), atezolizumab + platinum (RR, 0.65 , $95 \% \mathrm{Cl}, 0.18$ to 2.43 ), nivolumab ( $R R, 0.37,95 \% \mathrm{Cl}, 0.06$ to 2.61 ), pembrolizumab (RR, $0.30,95 \% \mathrm{Cl}, 0.06$ to 1.12 ), nivolumab + ipilimumab (RR, $0.1995 \% \mathrm{Cl}, 0.04$ to 0.92 ) (Fig. 4A). In terms of gastrointestinal irAEs, pembrolizumab had the lowest rate compared to nivolumab ( $R R, 0.92,95 \% \mathrm{Cl}, 0.42$ to 2.20 ), nivolumab + ipilimumab (RR, $0.64,95 \% \mathrm{Cl}, 0.25$ to 1.68 ), durvalumab ( $\mathrm{RR}, 0.45,95 \% \mathrm{Cl}, 0.17$ to 1.30 ), atezolizumab + platinum ( $R R, 0.40,95 \% \mathrm{Cl}, 0.18$ to 0.88$)$, and pembrolizumab + platinum ( $\mathrm{RR}, 0.33,95 \% \mathrm{Cl}, 0.15$ to 0.72 ) (Fig. 4B). For endocrine irAEs, pembrolizumab + platinum had the lowest rate compared to pembrolizumab (RR, $0.52,95 \% \mathrm{Cl}, 0.02$ to 12.18), atezolizumab + platinum ( $R R, 0.43,95 \% \mathrm{Cl}, 0.02$ to 7.44 ), durvalumab ( $R R, 0.55,95 \% \mathrm{Cl}, 0.03$ to 9.22 ), nivolumab (RR, $0.31,95 \%$ $\mathrm{Cl}, 0.01$ to 6.44 ), and nivolumab + ipilimumab (RR, $0.08,95 \% \mathrm{Cl}, 0.001$ to 2.58 ) (Fig. 4C). For pneumonitis, atezolizumab had the lowest rate compared to durvalumab ( $R R, 0.82,95 \% \mathrm{Cl}, 0.05$ to 10.42 ), nivolumab( $R R, 0.53,95 \% \mathrm{Cl}, 0.03$ to 9.30), atezolizumab + platinum ( $R R$, $0.29,95 \% \mathrm{Cl}, 0.03$ to 2.94 ), pembrolizumab + platinum ( $\mathrm{RR}, 0.23,95 \% \mathrm{Cl}, 0.02$ to 2.33 ), and pembrolizumab ( $\mathrm{RR}, 0.17,95 \% \mathrm{Cl}, 0.01$ to 1.77)(Fig. 4D). For liver irAEs, durvalumab had the lowest rate compared to pembrolizumab (RR, $0.92,95 \% \mathrm{Cl}, 0.23$ to 3.42 ), nivolumab (RR, $0.44,95 \% \mathrm{Cl}, 0.10$ to 2.13 ), atezolizumab + platinum ( $\mathrm{RR}, 0.41,95 \% \mathrm{Cl}, 0.10$ to 1.40 ), pembrolizumab + platinum (RR, $0.37,95 \% \mathrm{Cl}$, 0.10 to 1.31 ) (Fig. $4 \mathrm{E}$ ).

\subsection{Determining the ranking}


We ranked the probabilities of immune-related adverse events for all treatments by estimating the SUCRA value. A higher SUCRA value indicated a higher probability of irAEs and a poorer treatment regimen. For dermatologic irAEs, the corresponding ranking of incidences of the seven groups from low to high was: platinum-based chemotherapy(4.7\%), durvalumab(17.5\%), atezolizumab + platinum(39.9\%), pembrolizumab + platinum(43.3\%), nivolumab(67.1\%), pembrolizumab(80.1\%), nivolumab + ipilimumab(97.4\%)(Fig. 5A, supplementary figure S1A). For gastrointestinal irAEs, the corresponding ranking of incidences of the seven groups from low to high was: pembrolizumab(11.5\%), platinum-based chemotherapy(32.6\%), nivolumab(33.5\%), nivolumab + ipilimumab(40.3\%), atezolizumab + platinum(43.7\%), pembrolizumab + platinum(81.2\%), durvalumab(97.2\%)(Fig. 5B, supplementary figure S1B). For endocrine irAEs, the corresponding ranking of incidences of the seven groups from low to high was: platinum-based chemotherapy $(0.3 \%)$, pembrolizumab + platinum(33.5\%), nivolumab(45.7\%), atezolizumab + platinum(60.4\%), pembrolizumab(61.9\%), durvalumab(69.1\%), nivolumab + ipilimumab(79.1\%)(Fig. 5C, supplementary figure S1C). For pneumonitis, the corresponding ranking of incidences of the seven groups from low to high was: atezolizumab(14.6\%), platinum-based chemotherapy(21.6\%), nivolumab(40.3\%), durvalumab(40.8\%), atezolizumab + platinum(68.8\%), pembrolizumab + platinum(75.4\%), pembrolizumab(88.6\%)(Fig. 5D, supplementary figure S1D). For liver irAEs, the corresponding ranking of incidences of the six groups from low to high was: durvalumab(14.5\%), pembrolizumab(15.7\%), platinum-based chemotherapy(30.9\%), nivolumab(73.7\%), atezolizumab + platinum(74.8\%), pembrolizumab + platinum(90.4\%)(Fig. 5E, supplementary figure S1E).

\subsection{Model convergence, heterogeneity and publication bias}

As shown in supplementary figure S2, all comparisons of different irAEs all suggested that the contraction factor in Brookse-GelmaneRubin diagnostic plots were equal to the predefined cut-off value 1, suggesting that the study model had good convergence. In this network meta-analysis the comparisons showed low, medium or high heterogeneity(supplementary figure S3), then the random effects model was selected. The funnel plots were all symmetrically distributed, suggesting no publication bias(Fig. 6).

\subsection{Risk-of-bias assessment and sensitivity analysis}

As shown in Fig. 1, 9 included RCTs ${ }^{[13-14,18-24]}$ were regarded as high risk on blinding of participants and personnel and 5 included $\mathrm{RCTs}{ }^{[14-17,21]}$ were considered high risk on incomplete outcome data. Other domains indicated unclear risk or low risk. The

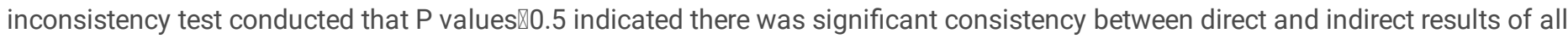
comparisons, and then the sensitivity analysis indicated stable results.

\section{Discussion}

Programmed cell death receptor-1 (PD-1) is a type I transmembrane glycoprotein ${ }^{[41]}$, which is an inhibitory receptor of $\mathrm{T}$ cells. It can bind and interact with the specific ligands PD-L1 (B7-H1) and PD-L2 (B7-H2). Tumor cells can activate PD-1, thereby promoting it to bind to PD-L1 and PD-L2 on the surface of antigen presenting cells, inhibiting the proliferation of effector $T$ cells and preventing $T$ cells from recognizing dangerous molecules in a timely and effective manner, thus enabling tumor cells to evade the pursuit of immune cells. PD1/PD-L1 inhibitors promote the activation and proliferation of T cells by inhibiting the expression of PD-1/PD-L1, thus stimulating the killing of tumor cells ${ }^{[42]}$. In recent years, since the PD-1/PD-L1 inhibitors nivolumab ${ }^{[43]}$, pembrolizumab ${ }^{[44]}$, atezolizumab ${ }^{[45]}$ and durvalumab ${ }^{[46]}$ were approved for NSCLC owing to their good clinical efficacy, a number of RCTs have successively evaluated PD-1/PDL1 inhibitor + chemotherapy, PD-1/PD-L1 inhibitor alone, dual PD-1/PD-L1 inhibitors combination versus chemotherapy in terms of efficacy and safety in the first-line treatment of advanced NSCLC. These RCTs suggested that the efficacy and treatment-related side effects of PD-1/PD-L1 inhibitor + chemotherapy, PD-1/PD-L1 inhibitor alone, dual PD-1/PD-L1 inhibitors combination combined with chemotherapy were better than chemotherapy alone, however the irAEs showed a tendency to be more prevalent in PD-1/PD-L1 inhibitors than in chemotherapy. Which immune-based treatment regimen is more likely to induce irAEs is controversial. The purpose of this study was to indirectly compare the probabilities of irAEs with different PD-1/PD-L1 inhibitor treatment regimens through an NMA.

In previous studies, Cheng Xu et al[26] compared the occurrences of irAEs with different immunotherapy regimens for all cancers in 2018. They found that atezolizumab had the best overall safety, while nivolumab had the best overall safety in the treatment of lung cancer with a combined approach. Xinru Chen et al ${ }^{[47]}$ investigated different immunotherapy regimens for immune-related pneumonia (IRP), and they concluded that PD-1/PD-L1 inhibitors increased the risk of IRP compared to chemotherapy and that PD-1/PD-L1 inhibitors + chemotherapy was associated with a lower risk of IRP than dual PD-1/PD-L1 inhibitors combination and PD-1/PD-L1 inhibitor monotherapy. Here, we indirectly compared the probability of irAEs caused by different specific PD-1/PD-L1 inhibitors-based treatment regimes for advanced NSCLC. And we conducted that, for dermatologic irAEs, the corresponding ranking of incidences from low to high was: platinum-based chemotherapy, durvalumab, atezolizumab + platinum, pembrolizumab + platinum, nivolumab, pembrolizumab,

Page 8/18 
nivolumab + ipilimumab. For gastrointestinal irAEs, the corresponding ranking of incidences from low to high was: pembrolizumab, platinum-based chemotherapy, nivolumab, nivolumab + ipilimumab, atezolizumab + platinum, pembrolizumab + platinum, durvalumab. For endocrine irAEs, the corresponding ranking of incidences from low to high was: platinum-based chemotherapy, pembrolizumab + platinum, nivolumab, atezolizumab + platinum, pembrolizumab, durvalumab, nivolumab + ipilimumab. For pneumonitis, the corresponding ranking of incidences from low to high was: atezolizumab, platinum-based chemotherapy, nivolumab, durvalumab, atezolizumab + platinum, pembrolizumab + platinum, pembrolizumab. For liver irAEs, the corresponding ranking of incidences from low to high was: durvalumab, pembrolizumab, platinum-based chemotherapy, nivolumab, atezolizumab + platinum, pembrolizumab + platinum. These conductions will help clinicians manage life-threatening treatment-related adverse events, optimize future trial designs, and modify the prescription of $\mathrm{ICl}$ drugs.

All of the articles included in this NMA were RCTs showing good consistancy. The Cochrane risk bias assessment tool were used to examine the quality of included studies and to ensure their inherent authenticity by assessing the potential risk of bias in various aspects of RCT design, implementation, and outcome evaluation. Compared to previous studies, first, more patients with advanced NSCLC were included in this study, and all data were up to date. Second, this study only looked at NSCLC, and immune-related treatment regimens were more specific to each treatment regimen, which will help clinicians make better treatment choices based on patients' specific conditions. Third, all of the control experiments in our study were platinum-based chemotherapy, excluding docetaxel-based chemotherapy and others, which would reduce bias and increase credibility. Fourth, some conclusions this study drew were innovative compared to previous studies, which will have some significance for guiding clinical treatment and subsequent studies.

In all of the studies of irAEs included, almost all comparisons showed low heterogeneity except for some comparisons, from which we can see this study has several limitations. First, different terms were used to describe irAEs in the RCTs. Although we found that the rating systems and terminology used in the reports were consistent and compatible, the diagnosis of each irAE was based solely on the experience of each clinician, rather than on a centralized review, which can lead to bias in irAE evaluation. Second, some irAEs were delayed diseases, and clinicians could not have observed the symptoms of patients within the clinical timeframe, leading to the loss of clinical data, which would bring some potential heterogeneity to this study. Third, the median follow-up time for each RCT was different, which would increase the frequency of irAEs associated with immunotherapy and increase the confounding factors for these events.

Fourth, the integration of different drugs with similar mechanisms into the same arm may lead to heterogeneity and bias. Fifth, although we included the latest RCT data that could be retrieved, some studies had a small sample size, so that further updates and experiments are still needed.

\section{Conclusions}

Although several limitations applied, this systematic review and NMA suggested that, for patients with advanced NSCLC at high risk of irAEs, durvalumab for patients with dermatologic and liver irAEs, pembrolizumab for patients with gastrointestinal irAEs, pembrolizumab+platinum for patients with endocrine irAEs, and atezolizumab for patients with pneumonitis may be the preferred treatment regimens rather than other immune-based therapies.

\section{Abbreviations}

PD-1: programmed cell death receptor 1

PD-L1: programmed cell death ligand-1

irAEs: immune-related adverse events

NSCLC: non-small cell lung cancer

RCTs: randomized clinical trials

RRs: risk ratios

NMA: network meta-analysis

PRISMA: preferred reporting items for systematic reviews and meta-analysis

MCMC: Markov chain Monte Carlo

Page $9 / 18$ 


\section{Declarations}

\section{Ethics approval and consent to participate}

This network meta-analysis is a data reintegration based on the original data, which does not involve ethics.

\section{Consent for publication}

Not applicable.

\section{Availability of data and material}

Some or all data, models, or code generated or used during the study are available from the first author by request.

\section{Competing interests}

Not applicable.

\section{Funding}

This research received no external funding.

\section{Authors' contributions:}

Author GHH(Doctor) and CMB have given substantial contributions to the conception or the design of the manuscript, author JJG and author WDZ to acquisition, analysis and interpretation of the data.All authors have participated to drafting the manuscript,author GHH revised it critically. All authors read and approved the final version of the manuscript. All authors contributed equally to the manuscript and read and approved the final version of the manuscript.

\section{Acknowledgements}

We thank the members of Second People's Hospital affiliated to Bengbu Medical College,the member of Xixi Hospital of Hangzhou for the critical comments and discussion on the manuscript.

\section{References}

1. Siegel RL, Miller KD, Jemal A. Cancer statisticsCA Cancer J Clin. 2020;70:7-30.

2. Goldstraw P, Chansky K. J. Crowley. The IASLC Lung Cancer Staging Project: Proposals for Revision of the TNM Stage Groupings in the Forthcoming(Eighth) Edition of the TNM Classification for Lung Cancer. Journal of Thoracic Oncology. 2016;11(1):39-51.

3. Torre LA, Bray F, Siegel RL, Ferlay J, et al. cancer statistics 2012. CA Cancer J Clin. 2015;65:87-108.

4. R.Yang MolinaJ. P.Cassivi, et al. Non-small cell lung cancer: Epidemiology, risk factors, treatment, and survivorship. Mayo Clin. 2008;83:584-94.

5. Bironzo P, Di Maio. A review of guidelines for lung cancer. J Thorac Dis. 2018;10(Suppl. 13):1556-663.

6. Torre L, Siegel R, Jemal A. Lung cancer statistics. Adv Exp Med Biol. 2016;893:1-19.

7. Sandler A, Gray R, Perry MC, et al. Paclitaxel-carboplatin alone or with bevacizumab for non-small-cell lung cancer. N Engl J Med. 2006;355:2542-50.

8. Scagliotti P. Pawel, et al. Phase III study comparing cisplatin plus gemcitabine with cisplatin plus pemetrexed in chemotherapynaive patients with advanced-stage non-small-cell lung cancer. J Clin Oncol. 2008;26:3543-51.

9. Ettinger, Wood A, et al. Non-small cell lung cancer, Version 5.2017, NCCN Clinical Practice Guidelines in Oncology. J Natl Compr Canc Netw. 2017;15:504-35.

10. Hanna N, Johnson D, Temin S, et al. Systemic therapy for stage IV non-small-cell lung cancer: American Society of Clinical Oncology Clinical Practice Guideline Update. J Clin Oncol. 2017;35:3484-515. 
11. Remon J, Passiglia F, Ahn M-J, et al. Immune checkpoint inhibitors in thoracic malignancies: review of the existing evidence by an IASLC expert panel and recommendations. J Thorac Oncol. 2020;15:914-47.

12. lams WT, Porter J, Horn L. Immunotherapeutic approaches for small cell lung cancer. Nat Rev Clin Oncol. 2020;17:300-12.

13. Carbone DP, Reck M, Paz-Ares L. First-line Nivolumab in stage IV or recurrent non-small-cell lung cancer. N Engl J Med. 2017;376:2415-26.

14. Naiyer A, Byoung C, Niels. Reinmuth. Durvalumab with or without tremelimumab vs standard chemotherapy in first-line treatment of metastatic non-small cell lung cancer. JAMA Oncology. 2020;6(5):237-51.

15. Paz-Ares L, Luft A, Vicente D. Pembrolizumab plus chemotherapy for squamous non-small-cell lung cancer. N Engl J Med. 2018;379:2040-51.

16. Gandhi L, Rodríguez-Abreu D, Gadgeel S. Pembrolizumab plus chemotherapy in metastatic non-small-cell lung cancer. N Engl J Med. 2018;378:2078-92.

17. Tony SK, Yi-Long Wu I, Kudaba. Pembrolizumab versus chemotherapy for previously untreated, PD-L1-expressing, locally advanced or metastatic non-small-cell lung cancer (KEYNOTE-042): a randomised, open-label, controlled, phase 3 trial. The Lancet. 2019;6736:32409-21.

18. Reck M. Delvys Rodríguez-Abreu. Pembrolizumab versus chemotherapy for PD-L1-positive non-small-cell lung cancer. N Engl J Med. 2016;375:1823-33.

19. Corey JL, Shirish MG, Hossein. Borghaei. Carboplatin and pemetrexed with or without pembrolizumab for advanced, non-squamous non-small-cell lung cancer: a randomised, phase 2 cohort of the open-label KEYNOTE-021 study. The Lancet. 2016;17(11):30498510 .

20. Barlesi F, Nishio M, Cobo M. Efficacy of atezolizumab (atezo) 1 carboplatin (carbo)/cisplatin (cis) 1 pemetrexed (pem) as $1 \mathrm{~L}$ treatment in key subgroups with stage IV non-squamous non-small cell lung cancer (NSCLC). Ann Oncol. 2018;29:743-4.

21. Robert Jotte, Federico C, Ihor V. Atezolizumab in combination with carboplatin and nab-paclitaxel in advanced squamous NSCLC (IMpower131): Results from a randomized phase III trial. Journal of Thoracic Oncology. 2020;3:28-38.

22. Howard West MM, Maen H. Atezolizumab in combination with carboplatin plusnab-paclitaxel chemotherapy compared with chemotherapy alone as first-line treatment for metastatic non-squamous non-small-cell lung cancer (IMpower130): a multicentre, randomised, open-label, phase 3 trial. Lancet Oncol. 2019;20:924-37.

23. Roy SH, Giuseppe G, Filippo DM. Atezolizumab for first-line treatment of PD-L1-selected patients with NSCLC. N Engl J Med. 2020;383:1328-39.

24. Hellmann MD, Paz-Ares L, Bernabe R. Nivolumab plus ipilimumab in advanced non-small-cell lung cancer. N Engl J Med. 2019;381:2020-31.

25. Cheng Xu Y-P, Chen X-J, Du. Comparative safety of immune checkpoint inhibitors in cancer:systematic review and network metaanalysis.BMJ. 2018; 363: k4226.

26. Liberati A, Altman DG, Tetzlaff J. The PRISMA statement for reporting systematic reviews and meta-analyses of studies that evaluate healthcare interventions: explanation and elaboration. BMJ. 2009;339:b2700.

27. Hutton B, Salanti G, Caldwell DM. The PRISMA extension statement for reporting of systematic reviews incorporating network metaanalyses of health care interventions: checklist and explanations. Ann Intern Med. 2015;162:777-84.

28. Jadad AR, Moore RA, Carroll D. Assessing the quality of reports of randomized clinical trials: is blinding necessary? Control Clin Trials. 1996;17(1):1-12.

29. Higgins J, Green S. Cochrane handbook for systematic reviews of interventions Version 5.1. 0. The Cochrane Collaboration.Confidence intervals. 2011.

30. Basch, lasonos McDonough. Patient versus clinician symptom reporting using the National Cancer Institute Common Terminology Criteria for Adverse Events: results of a questionnaire-based study. Lancet Oncology. 2016;7(11):903-9.

31. Salanti G, Higgins JPT, Ades AE, et al. Evaluation of networks of randomized trials. Stat Methods Med Res. 2008;17:279-301.

32. Sutton A, Ades AE, Cooper N, Abrams K. Use of indirect and mixed treatment comparisons for technology assessment. Pharmacoeconomics. 2008;26:753-67.

33. Mills EJ, Thorlund K, loannidis JP. Demystifying trial networks and network meta-analysis. BMJ. $2013 ; 346: f 2914$.

34. Higgins JP, Thompson SG, Deeks JJ, Altman DG. Measuring inconsistency in meta-analyses. BMJ. 2003;327:557-60. 
35. Salanti G, Ades AE, loannidis JP. Graphical methods and numerical summaries for presenting results from multiple-treatment metaanalysis: An overview and tutorial. J Clin Epidemiol. 2011;64:163-71.

36. Higgins JP, Jackson D, Barrett JK, Lu G, Ades AE, White IR. Consistency and inconsistency in network meta-analysis: concepts and models for multi-arm studies. Res Synth Methods. 2012;3:98-110.

37. Dias S, Welton NJ, Caldwell DM, Ades AE. Checking consistency in mixed treatment comparison meta-analysis. Stat Med. 2010;29:932-44.

38. Furukawa TA, Salanti G, Atkinson LZ, et al. Comparative efficacy and acceptability of first-generation and second-generation antidepressants in the acute treatment of major depression: protocol for a network meta-analysis. BMJ Open. 2016;6:e010919.

39. Sterne JA, Egger M. Funnel plots for detecting bias in meta-analysis: Guidelines on choice of axis. J ClinEpidemiol. 2001;54:104655.

40. He J, Hu Y, Hu M, et al. Development of PD-1/PD-L1·pathway in tumor immune microenvironment and treatment for non-small cell lung cancer. Sci Rep. 2015;5:13100.

41. Pedoeem A, Azoulay Al, Strazza M, et al. Programmed death-1 pathway in cancer and autoimmunity. Clin Immunol. 2014;153(1):145-52.

42. Kazandjian D, Suzman DL, Blumenthal G. FDA approval summary: Nivolumab for the treatment of metastatic non-small cell lung cancer with progression on or after platinum-based chemotherapy. Oncologist. 2016;21:634-42.

43. Pai-Scherf L, Blumenthal GM, Li H. FDA approval summary: Pembrolizumab for treatment of metastatic non-small cell lung cancer: First-line therapy and beyond. Oncologist. 2017;22:1392-9.

44. Weinstock C, Khozin S, Suzman D. U.S. Food and Drug Administration approval summary: Atezolizumab for metastatic non-small cell lung cancer. Clin Cancer Res. 2017;23:4534-9.

45. Antonia SJ, Villegas A, Daniel D. Durvalumab after Chemoradiotherapy in stage III non-small-cell lung cancer. N Engl J Med. 2017;377:1919-29.

46. Chen X, Zhang Z, Hou X. Immune-related pneumonitis associated with immune checkpoint inhibitors in lung cancer: a network meta-analysis. Journal for ImmunoTherapy of Cancer. 2020;8:e001170.

47. A.

\section{Figures}


A

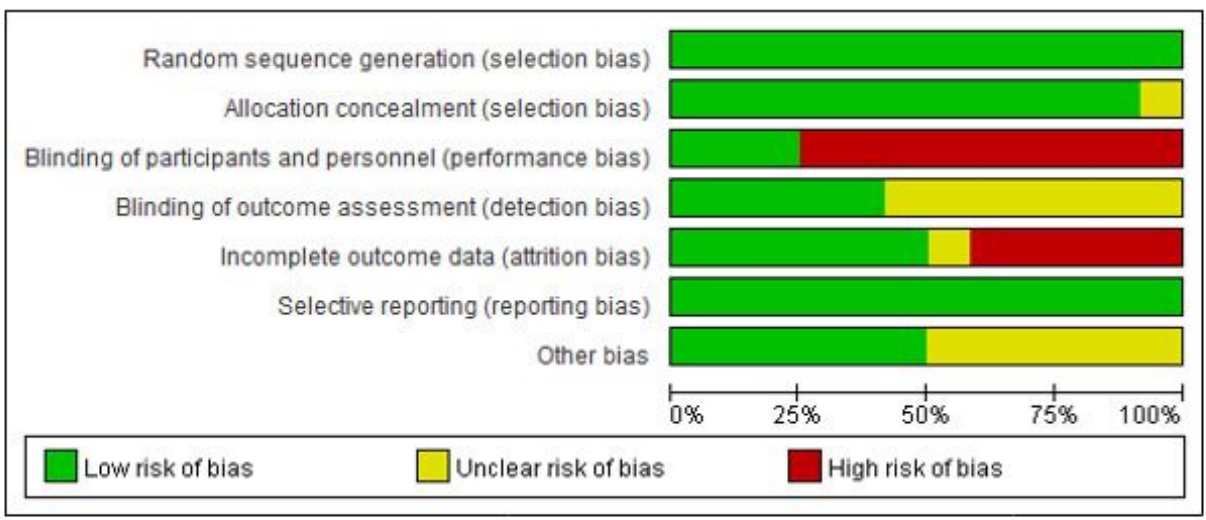

B

\begin{tabular}{|c|c|c|c|c|c|c|c|c|c|c|c|c|}
\hline 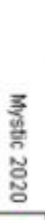 & 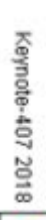 & 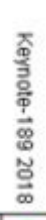 & 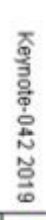 & 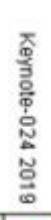 & 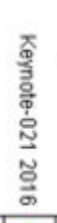 & 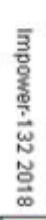 & 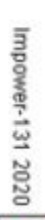 & 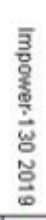 & 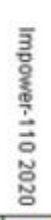 & 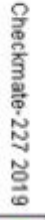 & 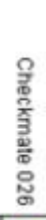 & \\
\hline$\odot$ & $\odot$ & $\odot$ & $\bullet$ & $\odot$ & $\odot$ & $\odot$ & $\odot$ & $\bullet$ & $\odot$ & $\odot$ & $\odot$ & Random sequence generation (selection bias) \\
\hline 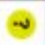 & $\odot$ & $\odot$ & $\odot$ & $\odot$ & $\odot$ & $\odot$ & $\odot$ & $\odot$ & ( & $\odot$ & $\odot$ & Allocation concealment (selection bias) \\
\hline 9 & $\odot$ & $\odot$ & $\odot$ & (1) & 0 & 0 & 0 & 0 & (2) & (1) & 0 & Blinding of participants and personnel (performance bias) \\
\hline$\sim$ & $\odot$ & $\sim$ & $\sim$ & $\odot$ & $\odot$ & $\sim$ & 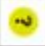 & $\omega$ & $\bullet$ & $\odot$ & $\odot$ & Blinding of outcome assessment (detection bias) \\
\hline ? & P & ? & (2) & $\odot$ & $\odot$ & $\odot$ & ? & $\bullet$ & $\odot$ & $\odot$ & $\odot$ & Incomplete outcome data (attrition bias) \\
\hline$\odot$ & $\odot$ & $\odot$ & $\odot$ & $\odot$ & $\odot$ & $\odot$ & $\odot$ & $\odot$ & ( & $\odot$ & $\odot$ & Selective reporting (reporting bias) \\
\hline 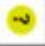 & $\sim$ & 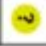 & $\sim$ & $\odot$ & $\odot$ & $\odot$ & $\odot$ & $\sim$ & $\odot$ & $\odot$ & $\odot$ & Other bias \\
\hline
\end{tabular}

Figure 1

The Cochrane risk bias assessment tool was used to evaluate bias from seven key sources: 1. Random sequence generation; 2. Allocation concealment; 3 . Blindness of subjects and researchers; 4 . Blindness of outcome evaluation; 5 . Incomplete data; 6 . Selective reporting of results; 7. Other biases. Green represents low risk, yellow represents unclear risk, and red represents high risk. (A) Risk of bias graph; (B) Risk of bias summary. 


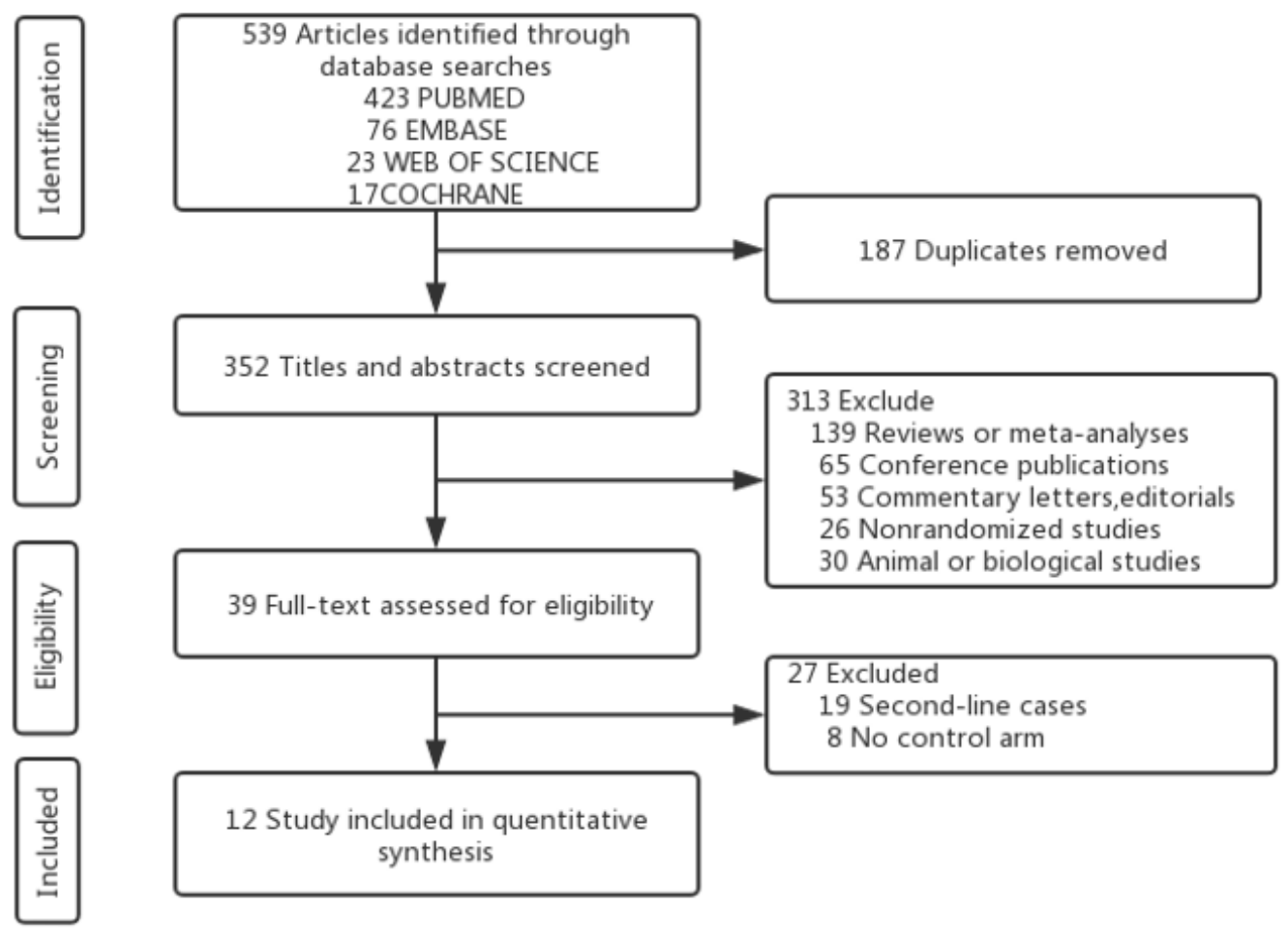

\section{Figure 2}

Flowchart of the systematic search PRISMA flow diagram 
A

Network evidence plot for Dermatologic,Gastrointestinal and Endocrine irAEs

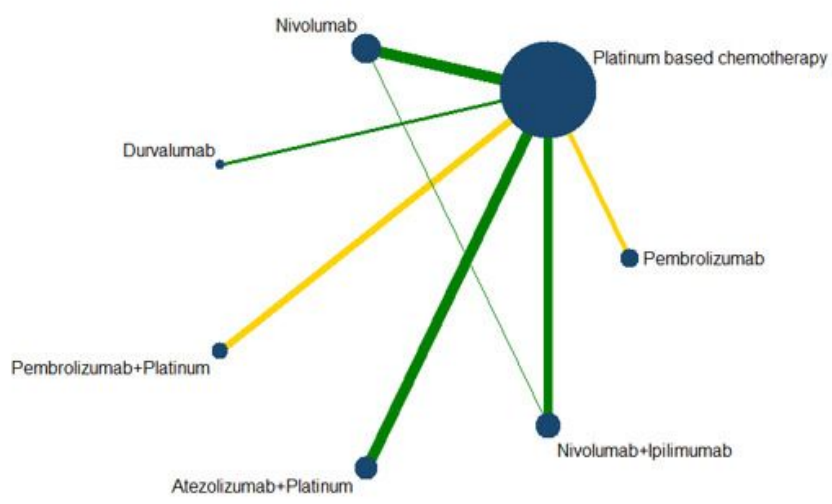

B

\section{Network evidence plot for Pneumonitis}

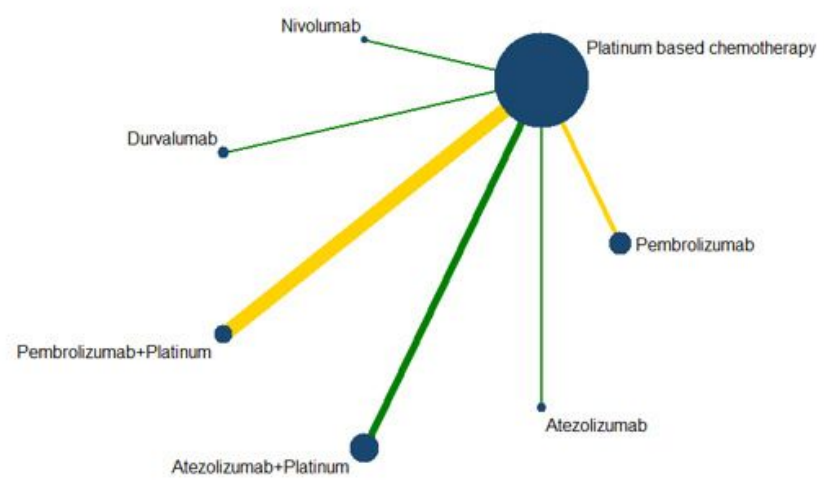

$\mathrm{C}$

Network evidence plot for Liver irAEs

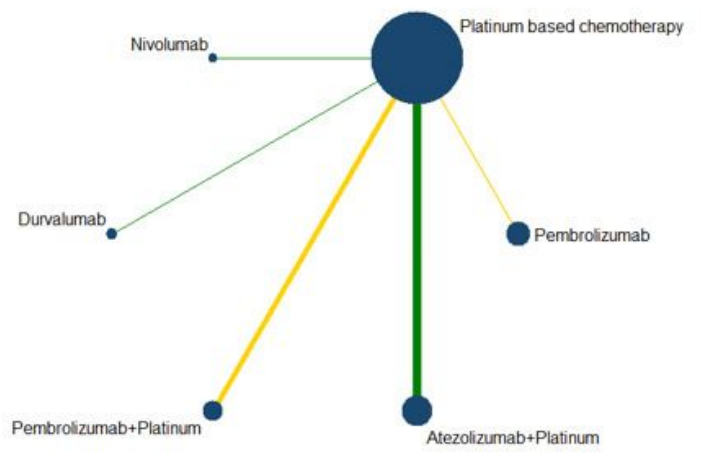

Figure 3

Network diagrams of comparisons on all outcomes in this network meta-analysis. (A) Comparisons on dermatologic,gastrointestinal and endocrine irAEs in patients with advanced NSCLC. (B) Comparisons on pneumonitis in patients with advanced NSCLC. (C) Comparisons on liver irAEs in patients with advanced NSCLC.(The circles represent treatment regimens and the size of each circle represents the number of participants, while the yellow line represents double-blind RCTs and the green is not blind.) 


\begin{tabular}{|c|c|c|c|c|c|c|}
\hline um & $0.65(0.18 .2 .43)$ & $1.56(0.56 .4 .40)$ & $3.35(0.99,11.96)$ & $2.13(0.82 .7 .12)$ & $1.05(0.42 .2 .74)$ & $0.54(0.28,1.03)$ \\
\hline $1.54(0.41 .5 .60)$ & Durvalumab & $2.39(0.60 .9 .50)$ & $5.14(1.09,23.77)$ & $3.29(0.90 .15 .40)$ & $1.61(0.44,6.02)$ & $0.82(0.27,2.53)$ \\
\hline $0.64(0.23,1.79)$ & $0.42(0.11,1.66)$ & Nivolumab & $2.15(0.76,6.19)$ & $1.37(0.48 .4 .98)$ & $0.67(0.24,1.95)$ & $0.34(0.15,0.78)$ \\
\hline $0.30(0.08 .1 .01)$ & $0.19(0.04,0.92)$ & $0.47(0.16 .1 .31)$ & Nivolumab + Iplimuma & $0.64(0.19,2.80)$ & $0.31(0.09,1.11)$ & $0.16(0.06,0.46)$ \\
\hline $0.47(0.14,1.23)$ & $0.30(0.06,1.12)$ & $0.73(0.20 .2 .09)$ & $1.57(0.36 .5 .40)$ & Pembrolizumab & $0.49(0.15,1.35)$ & $0.25(0.09,0.53)$ \\
\hline $0.95(0.37 .2 .39)$ & $0.62(0.17 .2 .26)$ & $1.48(0.51 .4 .20)$ & $3.20(0.90 .11 .05)$ & $2.04(0.74,6.88)$ & Pembrolizumab $+p$ & $0.51(0.25,0.99)$ \\
\hline $1.86(0.97,3.62)$ & $1.21(0.40 .3 .72)$ & $2.91(1.29 .6 .55)$ & $6.27(2.20,18.15)$ & $4.00(1.90,10.78)$ & $1.97(1.01 .3 .96)$ & Platinum \\
\hline
\end{tabular}

B

\begin{tabular}{|c|c|c|c|c|c|c|}
\hline ezolizumab+Platinum & $0.89(0.31,2.26)$ & $0.44(0.19,0.93)$ & $0.63(0.25,1.55)$ & $0.40(0.18,0.88)$ & $1.22(0.58,2.49)$ & $0.71(0.40 .1 .15)$ \\
\hline $1.12(0.44,3.21)$ & Durvalumab & $0.49(0.18,1.37)$ & $0.70(0.25 .2 .21)$ & $0.45(0.17,1.30)$ & $1.36(0.54,3.80)$ & $0.80(0.36,1.87)$ \\
\hline $2.29(1.07 .5 .25)$ & $2.04(0.73,5.46)$ & Nivolumab & $1.42(0.68,3.21)$ & $0.92(0.42,2.20)$ & $2.75(1.32,6.17)$ & $1.63(0.91,2.93)$ \\
\hline $1.60(0.65,3.95)$ & $1.42(0.45,4.02)$ & $0.71(0.31,1.46)$ & Nivolumab + Ipilimumab & $0.64(0.25,1.68)$ & $1.91(0.80 .4 .68)$ & $1.14(0.53,2.30)$ \\
\hline $2.53(1.14,5.47)$ & $2.25(0.77,5.77)$ & $1.09(0.45,2.40)$ & $1.56(0.60 .3 .96)$ & Pembrolizumab & $3.02(1.38,6.57)$ & $1.77(0.95,3.09)$ \\
\hline $0.82(0.40 .1 .71)$ & $0.73(0.26 .1 .84)$ & $0.36(0.16,0.76)$ & $0.52(0.21,1.26)$ & $0.33(0.15,0.72)$ & Pembrolizumab+P & $0.59(0.34,0.95)$ \\
\hline $1.41(0.87,2.47)$ & $1.25(0.53 .2 .77)$ & $0.61(0.34,1.10)$ & $0.88(0.43,1.90)$ & $0.57(0.32,1.05)$ & $1.69(1.05 .2 .90)$ & Platinum \\
\hline
\end{tabular}

C

\begin{tabular}{|c|c|c|c|c|c|c|}
\hline tezolizumab+Platinum & $1.12(0.02,67.61)$ & $1.41(0.06 .70 .63)$ & $5.39(0.14,796.37)$ & $0.85(0.03,19.70)$ & $0.43(0.02 .7 .44)$ & $0.10(0.01,0.71)$ \\
\hline $0.89(0.01,65.68)$ & Durvalumab & $1.26(0.02,208.47)$ & $4.78(0.06,2043.79)$ & $0.74(0.01,61.35)$ & $0.38(0.01,23.13)$ & $0.09(0.00 .3 .11)$ \\
\hline $0.71(0.01 .16 .28)$ & $0.79(0.00 .47 .20)$ & Nivolumab & $3.84(0.19,141.79)$ & $0.60(0.01,15.93)$ & $0.31(0.01,6.44)$ & $0.07(0.00,0.69)$ \\
\hline $0.19(0.00 .6 .96)$ & $0.21(0.00 .17 .99)$ & $0.26(0.01,5.17)$ & Nivolumab + Ipilimumak & $0.16(0.00,6.58)$ & $0.08(0.001 .2 .58)$ & $0.02(0.00,0.33)$ \\
\hline $1.18(0.05 .37 .96)$ & $1.35(0.02,105.26)$ & $1.65(0.06 .127 .70)$ & $6.32(0.15,1467.35)$ & Pembrolizumab & $0.52(0.02,12.18)$ & $0.12(0.01 .1 .41)$ \\
\hline $2.30(0.13,51.29)$ & 152.90) & $3.24(0.16 .176 .01)$ & $12.45(0.39,2137.95)$ & $1.92(0.08,48.12)$ & Pembrolizumab+Pl & $0.22(0.03 .1 .75)$ \\
\hline $10.23(1.40 .106 .41)$ & $11.57(0.3$ & $14.50(1.45 .436 .81)$ & $55.39(2.99,6153.36)$ & $8.68(0.71,107.58)$ & $4.47(0.57,33.34)$ & Platinum \\
\hline
\end{tabular}

$\mathrm{D}$

\begin{tabular}{|c|c|c|c|c|c|c|}
\hline Atezolizumab & $3.42(0.34,39.76)$ & $1.83(0.11 .33 .46)$ & $1.88(0.11,36.09)$ & $5.80(0.56 .92 .10)$ & $4.37(0.43 .64 .22)$ & $1.37(0.18,10.80)$ \\
\hline $0.29(0.03 .2 .94)$ & ezolizumab+Plat & $0.54(0.05,5.56)$ & $0.55(0.05,5.76)$ & $1.68(0.29 .12 .74)$ & $1.27(0.22,9.67)$ & $0.40(0.11 .1 .24)$ \\
\hline $0.55(0.03,9.22)$ & $1.84(0.18 .20 .45)$ & Durvalumab & $1.02(0.06,17.66)$ & $3.06(0.31,47.88)$ & $2.35(0.23 .34 .86)$ & $0.74(0.10 .5 .67)$ \\
\hline $0.53(0.03 .9 .30)$ & $1.82(0.17,20.05)$ & $0.98(0.06 .17 .40)$ & Nivolumab & $3.07(0.29 .43 .74)$ & $2.30(0.23 .32 .99)$ & $0.73(0.09,5.65)$ \\
\hline $0.17(0.01,1.77)$ & $0.60(0.08,3.49)$ & $0.33(0.02,3.19)$ & $0.33(0.02,3.46)$ & Pembrolizumab & $0.75(0.09,5.97)$ & $0.24(0.05,0.86)$ \\
\hline $0.23(0.02,2.33)$ & $0.79(0.10 .4 .59)$ & $0.43(0.03,4.35)$ & $0.43(0.03,4.33)$ & $1.33(0.17,10.53)$ & Pembrolizumab+1 & $0.32(0.06 .1 .07)$ \\
\hline $0.73(0.09 .5 .57)$ & $2.49(0.80 .8 .78)$ & $1.35(0.18,10.17)$ & $1.37(0.18 .10 .78)$ & $4.20(1.16,22.04)$ & $3.16(0.93,15.93)$ & Pla \\
\hline
\end{tabular}

E

\begin{tabular}{|l|lllll|}
\hline Atezolizumab+Platinum & $0.41(0.10,1.40)$ & $0.91(0.23,3.11)$ & $0.44(0.15,1.16)$ & $1.11(0.40,2.78)$ & $0.50(0.23,0.93)$ \\
\hline $2.45(0.72,9.55)$ & Durvalumab & $2.26(0.47,10.18)$ & $1.09(0.29,4.35)$ & $2.70(0.76,9.96)$ & $1.22(0.41 .3 .66)$ \\
$1.09(0.32,4.36)$ & $0.44(0.10,2.13)$ & Nivolumab & $0.49(0.13,1.85)$ & $1.22(0.35,4.42)$ & $0.55(0.18,1.64)$ \\
$2.25(0.86,6.61)$ & $0.92(0.23,3.42)$ & $2.03(0.54,7.58)$ & Pembrolizumab & $2.51(0.91 .7 .01)$ & $1.11(0.51,2.38)$ \\
$0.90(0.36,2.52)$ & $0.37(0.10,1.31)$ & $0.82(0.23,2.84)$ & $0.40(0.14 .1 .10)$ & Pembrolizumab+Platinum $0.45(0.23,0.85)$ \\
$2.02(1.07,4.43)$ & $0.82(0.27,2.46)$ & $1.82(0.61,5.42)$ & $0.90(0.42,1.95)$ & $2.24(1.18,4.38)$ & Platinum \\
\hline
\end{tabular}

\section{Figure 4}

Pooled estimates of the network meta-analysis. (A) Multiple treatment comparison for dermatologic irAEs based on network consistency. (B) Multiple treatment comparison for gastrointestinal irAEs based on network consistency model. (C) Multiple treatment comparison for endocrine irAEs based on network consistency model. (D) Multiple treatment comparison for pneumonitis based on network consistency model. (E) Multiple treatment comparison for liver irAEs based on network consistency model. (OR囚1 means the treatment in top left is worse;Platinum=Platinum based chemotherapy). 

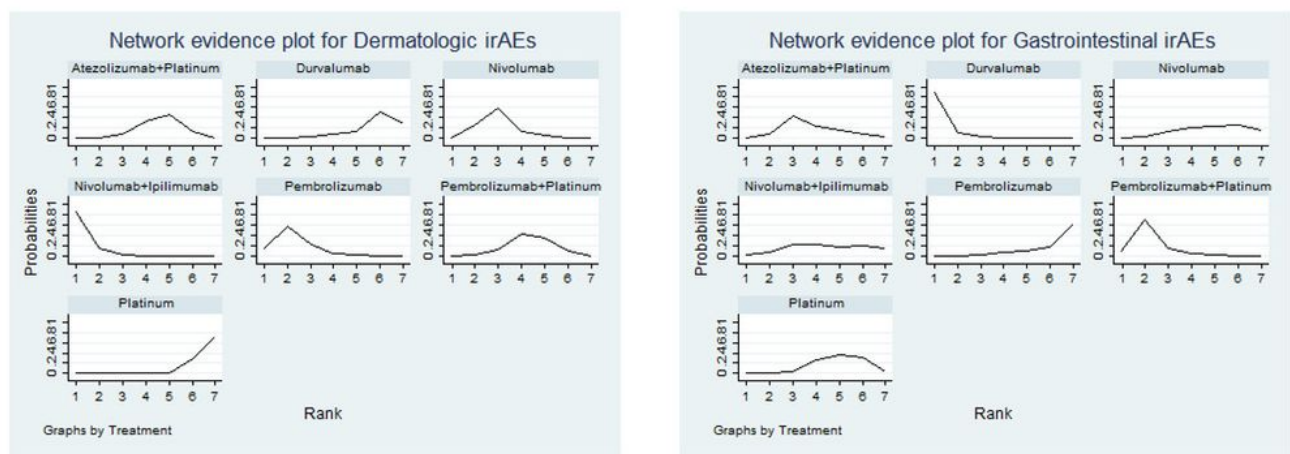

$\mathrm{C}$

D
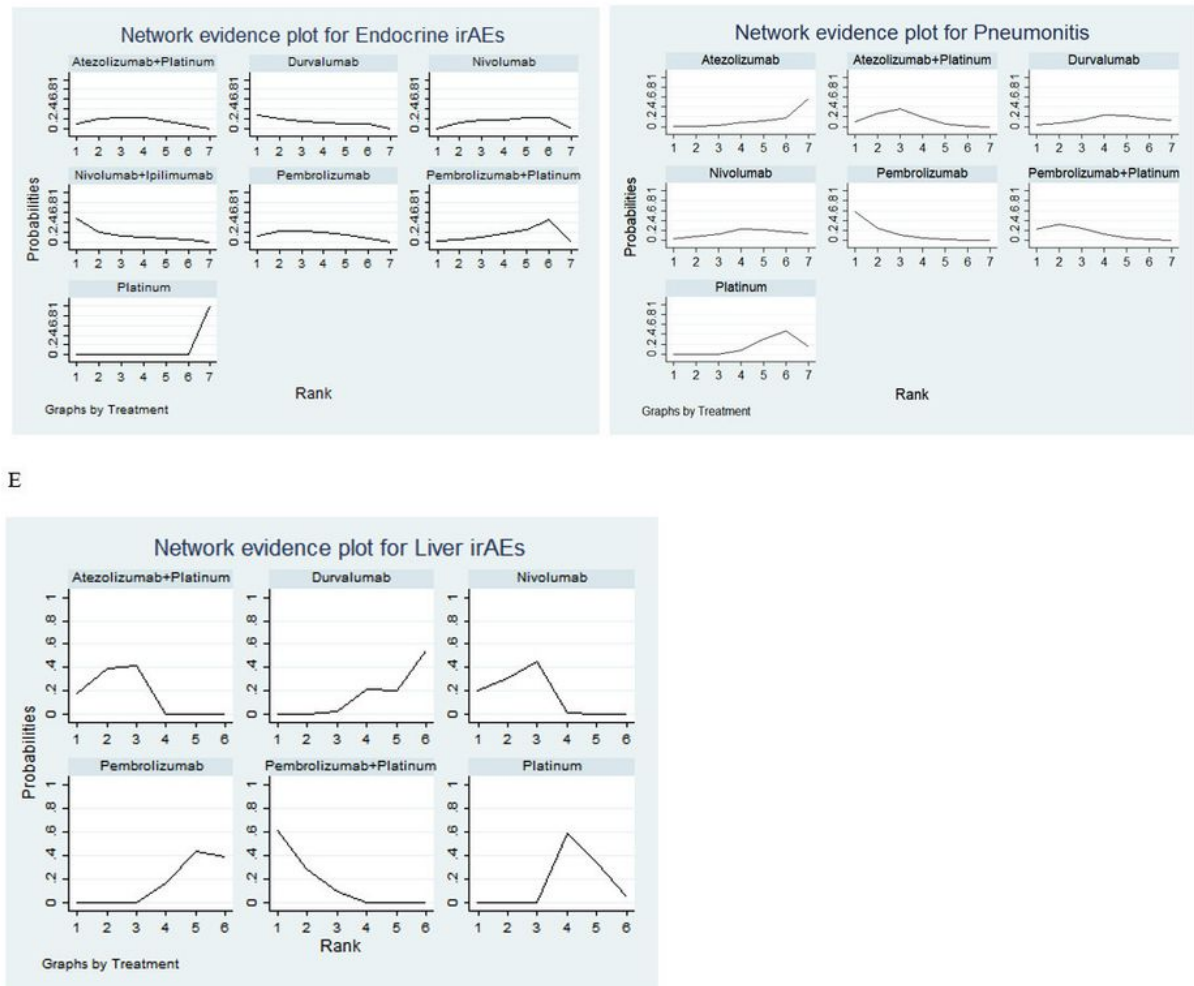

\section{Figure 5}

Sequence diagram of the network meta-analysis. (A) Multiple treatment comparison for dermatologic irAEs based on Rank Probility.(B) Multiple treatment comparison for gastrointestinal irAEs based on Rank Probility.(C) Multiple treatment comparison for endocrine irAEs based on Rank Probility. (D) Multiple treatment comparison for pneumonitis based on Rank Probility. (E) Multiple treatment comparison for liver irAEs based on Rank Probility. ( Platinum=Platinum based chemotherapy). 
A

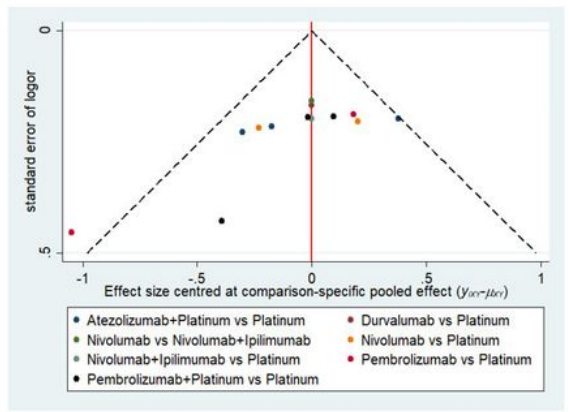

C

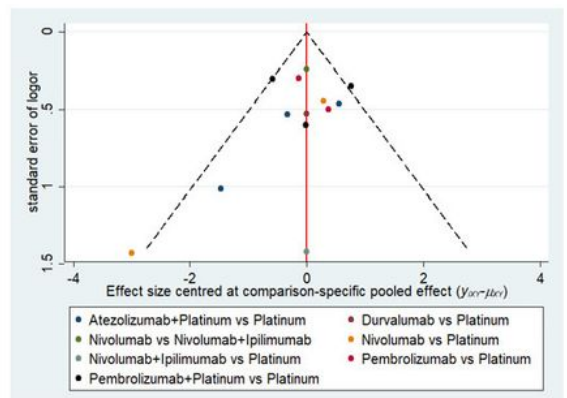

$B$

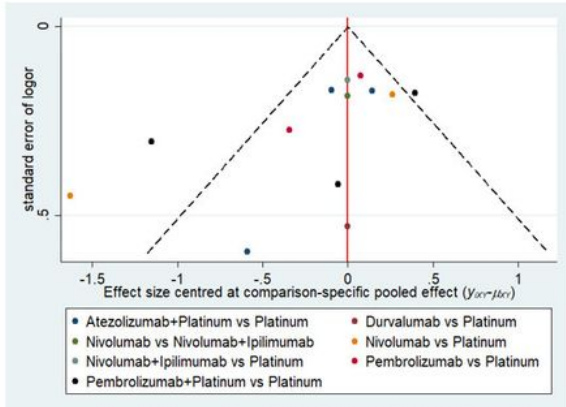

D

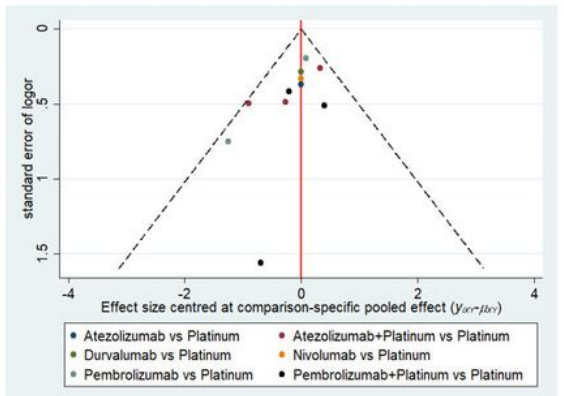

$\mathbf{E}$

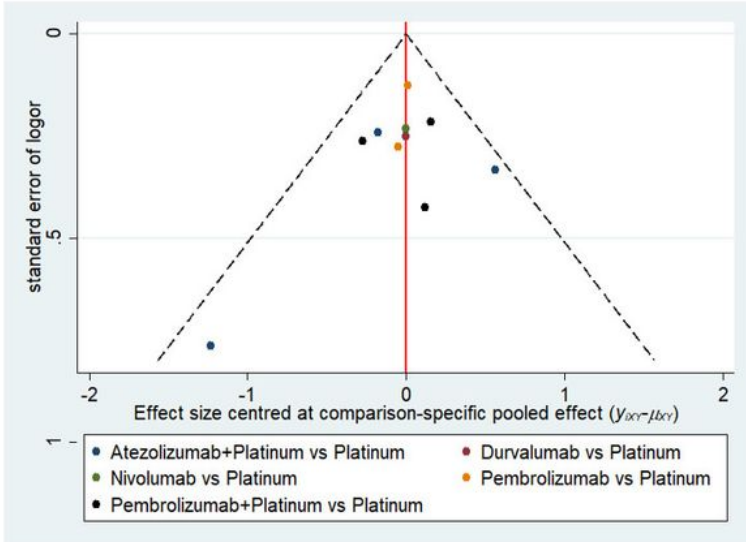

Figure 6

Funnel plot of (A)dermatologic irAEs, (B)gastrointestinal irAEs, (C)endocrine irAEs, (D)pneumonitis and (E)liver irAEs in the network metaanalysis. ( Platinum=Platinum based chemotherapy).

\section{Supplementary Files}

This is a list of supplementary files associated with this preprint. Click to download.

- SupplementaryMaterials.docx 